\title{
SUSPENDED-SEDIMENT-BASED BEACH MORPHOLOGY MODEL APPLIED TO SUBMERBGED GROIN SYSTEM
}

\author{
Yoshiyuki Uno ${ }^{1}$, Yoshimi Goda ${ }^{2}$, and Nobuyuki Ono ${ }^{3}$
}

\begin{abstract}
A beach morphology model based on sediment suspension and settlement is applied to a system of seven submerged groins, which have a function of reducing the speed of longshore currents and controlling beach erosion. Nearshore currents are computed with the PEGBIS model by Goda (2004) for directional random wave transformation, and beach morphology is estimated with the suspended sediment transport model by Katayama and Goda (2003) with a new suspension coefficient by Goda (2010). The computation indicates the efficacy of a submerged groin system for beach erosion control. Discussions are made on some aspects of the submerged groin system to be clarified through further investigations.
\end{abstract}

Keywords: Submerged groins, beach erosion, nearshore currents, suspended sediment transport, directional random waves

\section{Introduction}

Control of beach erosion has been tried with various means such as groins, detached breakwaters, beach fill, and others. Professor Goudas of University of Patras in Greece organized the first conference on Soft Shore Protection in 2001. Among various means of shore protection, discussion of submerged groins were presented by several authors. A group of submerged groins was said to be effective for enhancing sand accretion and preventing beach erosion. Holmberg (2001) demonstrated several successful cases in the United States but without any explanation of sand accretion mechanism. Goudas et al. (2001) presented a number of field applications and tried to explain the mechanism based on the 2D current analysis of bed layers. Aminti et al. (2001) also reported an experience of a submerged groin construction in Italy. Aminti et al. (2009) further investigated the field performance of the submerged groin system there, and tried to simulate its performance with a numerical model.

Submerged groins are made with geotubes being filled fresh concrete (Holmberg and Goudas et al.) or built with sand-filled geobags (Aminti et al.).

Though a submerged groin system seems to provide coastal engineers with an efficient and economical countermeasure against beach erosion, no reasonable explanation has been given for its mechanism of enhancing sand accretion. Goda et al. (2009) presented a numerical model in which submerged groins bring forth increase of bottom roughness in their downstream and function to reduce the speed of longshore currents induced by obliquely incident waves. Within the zone of weakened longshore currents, suspended sediment settles down quickly compared to the case without submerged groins. Numerical computation exhibited a decrease of longshore current velocity and little morphological change within the groin system. Beach accretion was not simulated, however.

A key parameter of suspended-sediment-based model is the rate of sediment pickup from the bottom by breaking waves. A new proposal of sediment pickup rate is being made by Goda (2010), which is introduced in the present paper.

\section{FUNDAMENTAL EQUATIONS FOR NUMERICAL SIMULATION}

\section{Wave Transformations by Random Breaking and Input Wave Spectrum}

The beach morphology model is developed for directional random waves. Transformation of directional random waves is computed with the PEGBIS model (Parabolic Equation with Gradational

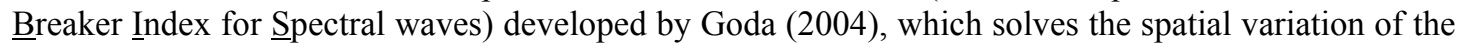
complex velocity potential $\phi$ with the following equation:

$$
\frac{\partial \phi}{\partial x}=\left\{i\left(k_{x}+\frac{k_{y}^{2}}{2 k_{x}}\right)-\frac{1}{2 k_{x} c c_{g}} \frac{\partial}{\partial x}\left(k_{x} c c_{g}\right)\right\} \phi+\frac{i}{2 k_{x} c c_{g}} \frac{\partial}{\partial y}\left(c c_{g} \frac{\partial \phi}{\partial y}\right)-f_{D} \phi
$$

\footnotetext{
${ }^{1}$ ECOH CORPORATION, 2-6-4 Kita-Ueno, Taito-Ku, Tokyo 110-0014, Japan. uno@ecoh.co.jp

${ }^{2}$ ECOH CORPORATION, ditto.goda@ecoh.co.jp

${ }^{3}$ ECOH CORPORATION, ditto. n-ono@ecoh.co.jp
} 
where $f_{D}$ is the coefficient of energy dissipation by bottom friction and gradational wave breaking, $k_{x}$ and $k_{y}$ are the $x$ and $y$ components of wave number, respectively, $c$ is the wave celerity, and $c_{g}$ is the group velocity. Please refer to Goda (2004) for details.

The input wave spectrum is the product of the JONSWAP-type frequency spectrum and the Mitsuyasu-type directional spectrum (Goda, 2000). The spectral density is specified as the function of the offshore significant wave height $H_{0}$ and the spectral peak period $T_{p}$. The peak enhancement factor is set at $\gamma=1$ for all the computations. The directional spreading parameter at the spectral peak is set at $s_{\max }=75$. The waves are incident at the offshore boundary with the angle of $\theta_{0}=20^{\circ}$ for the principal direction.

\section{Wave Setup and Nearshore Currents}

Computation is made by solving the following depth-integrated equations of continuity and momentum in minute time steps:

$$
\left.\begin{array}{l}
\frac{\partial \bar{\eta}}{\partial t}+\frac{\partial(D U)}{\partial x}+\frac{\partial(D V)}{\partial y}=0 \quad: \quad D=h+\bar{\eta} \\
\frac{\partial U}{\partial t}+U \frac{\partial U}{\partial x}+V \frac{\partial U}{\partial y}+g \frac{\partial \bar{\eta}}{\partial x}+R_{x}-L_{x}+F_{x}=0 \\
\frac{\partial V}{\partial t}+U \frac{\partial V}{\partial x}+V \frac{\partial V}{\partial y}+g \frac{\partial \bar{\eta}}{\partial y}+R_{y}-L_{y}+F_{y}=0
\end{array}\right\}
$$

where $h$ is the water depth, $U$ and $V$ are the depth-averaged velocity components in the $x$ and $y$ directions, respectively, $\bar{\eta}$ is the local mean water level, and $R, L$, and $F$ are the stresses acting on the water body being the sum of the radiation stress and the stress due to surface roller, the horizontal dispersion term, and the average shear stresses acting on the sea bottom, respectively, with the suffixes $x$ and $y$ indicating the respective components. The $x$ axis is on the shoreline and positive onshore.

The kinetic energy $E_{s r}$ of surface roller is assessed by solving the following equation in step by step from the offshore boundary after Tajima and Madsen (2003):

$$
\alpha\left[\frac{\partial}{\partial x}\left(E c_{g} \cos \theta\right)+\frac{\partial}{\partial y}\left(E c_{g} \sin \theta\right)\right]+\left[\frac{\partial}{\partial x}\left(E_{s r} c \cos \theta\right)+\frac{\partial}{\partial y}\left(E_{s r} c \sin \theta\right)\right]=-\frac{K_{s r}}{h} E_{s r} c
$$

The parameter $\alpha$ denotes a factor of energy transfer from breaking waves to surface roller, which is set at $\alpha=0.5$ after Goda $(2006,2008)$. The term $K_{s r}$ represents the rate of energy dissipation of surface roller, which is set as a function of the beach slope $s$ as below.

$$
K_{s r}=\frac{3}{8}(0.3+2.5 s)
$$

The turbulent eddy viscosity $v_{t}$ for evaluation the horizontal diffusion is estimated with the formula by Larson and Kraus (1991) of the following form:

$$
v_{t}=\Lambda u_{\max } H
$$

The constant $\Lambda$ is given a value of 0.25 for the area with the depth smaller than $4 \mathrm{~m}$, and it is gradually decreased to 0.00025 at the depth of $6 \mathrm{~m}$ and kept at that level toward the offshore boundary.

The average shear stress on the seabed is evaluated with the velocity vector of the sum of wave orbital velocity at seabed and nearshore currents after Nishimura (1980) as in the following:

$$
\begin{aligned}
& F_{x}=C_{f x} \overline{\left(U+u_{b}\right) \sqrt{\left(U+u_{b}\right)^{2}+\left(V+v_{b}\right)^{2}}} /(h+\bar{\eta}) \\
& F_{y}=C_{f y} \overline{\left(V+v_{b}\right) \sqrt{\left(U+u_{b}\right)^{2}+\left(V+v_{b}\right)^{2}}} /(h+\bar{\eta})
\end{aligned}
$$

The coefficient of friction $C_{f y}$ in the $y$ direction is given the value of 0.01 , but the coefficient of friction $C_{f x}$ in the $x$ direction is raised to 0.05 for three grids in the downstream side of each grid and 0.02 at the fourth grid while the rest of grids are given the value of 0.01 . An artificial increase of the 
friction coefficient is to simulate the roughness effect of submerged groins against longshore currents. A submerged groin causes a flow separation at the top and yields energy dissipation by vortex formation. Roughness increase is an artifice in 2D simulation of wave-induced current fields.

\section{Sediment Suspension by Breaking Waves}

The sediment transport model by Katayama and Goda (2000) is employed for assessing the morphological change of a beach. The model wholly depends on the process of sediment suspension by turbulence induced by breaking waves, transport of suspended sediment by nearshore currents, and its settlement with the fall velocity. The process of bed load transport by shear stress is not taken into account for morphological changes of beach bathymetry, based on the authors' assumption that storm waves and associated transport of suspended sediment is the primary actors of beach morphology.

The rate of sediment pick-up $q_{p}$ by breaking waves is assumed to be proportional to the dissipation rate of the wave energy flux as expressed in the following form:

$$
q_{p}=\left\{\begin{array}{cc}
-\frac{\beta_{s}}{\left(\rho_{s}-\rho_{w}\right) g h} \frac{\partial W}{\partial n} & : \frac{\partial W}{\partial n}<0 \\
0 & : \frac{\partial W}{\partial n} \geq 0
\end{array}\right.
$$

where $\beta_{s}$ is the suspension coefficient, $\rho_{s}$ and $\rho_{w}$ are the densities of sediments and water, respectively, and $W$ is the wave energy flux. The normal vector $n$ is taken in the direction of wave propagation. The sediment picked up from the seabed is suspended in the water and carried by the nearshore currents. The concentration of suspended sediment is assumed vertically uniform for the sake of simplicity under the circumstance of the 2D model of nearshore currents predicted by Eqs. (2) and (3).

Katayama and Goda (2000) expressed the suspension coefficient in the empirical formula of the following:

$$
\beta_{s}=0.76 \times \frac{w_{f} K_{1}}{g T_{0}}\left(s^{-1}+18 s^{0.4}\right)\left(H_{0} / L_{0}\right)^{-0.43}
$$

where $w_{f}$ is the fall velocity estimated with Rubey's formula, while $K_{1}$ is the constant in the CERC formula for longshore sediment transport rate and estimated by the empirical formula by Del Val et al. (1993) in the following form:

$$
K_{1}=0.8 \exp [-2.5 d]
$$

where $d$ is the median diameter of sediment in the units of mm.

The above formula was based on the assumption that the sediment transport rate predicted by the CERC formula wholly represents the contribution of suspended sediment. However, Goda (2010) has analyzed several sets of field measurements and large-scale laboratory data on suspended sediment concentration and evaluated the suspension coefficient through comparison of mean sediment concentration and dissipation rate of local wave energy flux. The suspension coefficient exhibits quite large scatter, but it can be represented with the following mean value with a $90 \%$ confidence interval:

$$
\beta_{s}=0.0045 \times 10^{ \pm 0.64}
$$

The multiplier of $10^{ \pm 0.64}$ indicates the range of $1 / 4.4$ to 4.4 . The new coefficient of Eq. (11) yields the value being one order smaller than the prediction by Eq. (9).

\section{Sediment Transport and Depth Change}

Sediments picked up from the seabed are advected and diffused by the nearshore currents, while being settled down by the gravity. The following equation by Katayama and Goda (2003) for the depth-averaged sediment concentration $\bar{c}$ is employed in the present numerical model:

$$
\frac{\partial(\bar{c} U h)}{\partial x}+\frac{\partial(\bar{c} V h)}{\partial y}-\varepsilon_{x} \frac{\partial^{2}(\bar{c} h)}{\partial x^{2}}-\varepsilon_{y} \frac{\partial^{2}(\bar{c} h)}{\partial y^{2}}+\bar{c} w_{f}=q_{p}
$$

where $\varepsilon_{x}$ and $\varepsilon_{y}$ denote the horizontal diffusion coefficients in the x and y directions, respectively.

The rate of depth change is computed with the following equation: 


$$
\frac{\partial h}{\partial t}=\frac{1}{1-\lambda}\left(q_{p}-\bar{c} w_{f}\right)
$$

where $\lambda$ denotes the porosity of sediment in the seabed.

\section{RESULTS OF NUMERICAL COMPUTATION}

\section{Beach Profile with Submerged Groin System and Computational Grids}

The coast considered herein is a planar beach having a straight shoreline and the isobaths are also straight and shore-parallel. The beach is given an equilibrium profile by Dean (1991) for the sediment with the median diameter of $d=0.3 \mathrm{~mm}$. The fall velocity estimated with Rubey's formula is $w_{f}=3.9$ $\mathrm{cm} / \mathrm{s}$ at the water temperature of $20^{\circ}$. Dean's equilibrium beach profile is expressed as

$$
h(x)=A x^{2 / 3} \quad: A=0.067 w_{f}^{0.44}
$$

in which the depth $h$ and the offshore distance $x$ is expressed in the units of $\mathrm{m}$, and the fall velocity is in the units of $\mathrm{cm} / \mathrm{s}$. Because the profile gives the infinite slope at $x=0$, the depths at three grid points around the shoreline are given a smoothing process to avoid singularity at the shoreline. The equilibrium profile is extended to the depth of $10.6 \mathrm{~m}$ at the distance of $800 \mathrm{~m}$, and then a uniform slope of about 1 on 130 is extended to the depth of $20 \mathrm{~m}$ over the distance of $1200 \mathrm{~m}$. The computational area has the cross-shore coverage of $2000 \mathrm{~m}$ and the alongshore coverage of $1600 \mathrm{~m}$

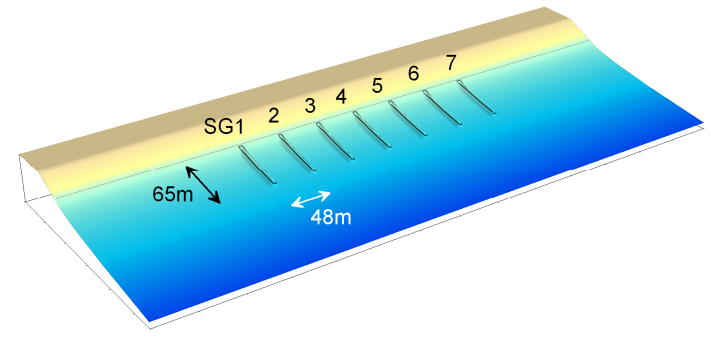

(a) Bird's-eye view

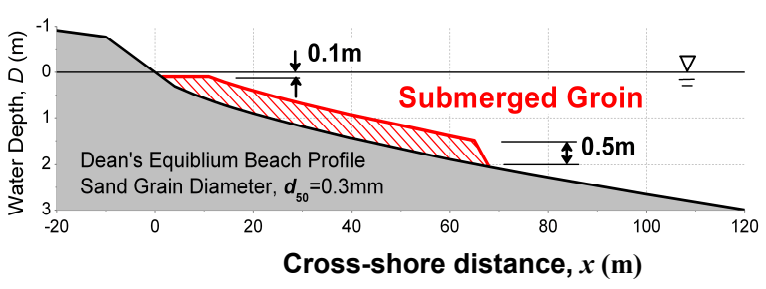

(b) Beach profile with submerged groin

Figure 1. Beach profile and layout of seven submerged groins.

Figure 1 shows the beach profile and the layout of seven submerged groins, which are extended to the depth of $2.0 \mathrm{~m}$ with the height of $0.5 \mathrm{~m}$ with the minimum submergence of $0.1 \mathrm{~m}$. The groins are installed with a mutual spacing of $48 \mathrm{~m}$ and have the extension of $65 \mathrm{~m}$.

The offshore boundary is set at the depth of $h=20 \mathrm{~m}$. The grid spacing in the cross-shore direction is $\Delta x=4 \mathrm{~m}$ up to $h=12 \mathrm{~m}$ and $\Delta x=16 \mathrm{~m}$ for $h=12 \sim 20 \mathrm{~m}$. The alongshore grid spacing is $\Delta y=4 \mathrm{~m}$. The computational time step is set at $\Delta t=0.025 \mathrm{~s}$ based on the result of trial computation. Each groin is assigned the width of one grid of $\Delta y=4 \mathrm{~m}$, even though actual designs will be made with a smaller width. The side boundary condition is the continuity of currents across the left and right sides of the boundary, i.e. the same current velocities inside and outside the boundary.

\section{Wave Field in the Nearshore Region}

The directional random incident waves are given with the dimensions of $H_{0}=2.0 \mathrm{~m}, T_{p}=8 \mathrm{~s}$, and $\theta_{0}=20^{\circ}$. The offshore deepwater wave steepness is $H_{0} / L_{0}=0.02$. The nearshore wave field calculated by the PEGBIS model is shown in Fig. 2, where the spatial variation of the root-mean-square wave height $H_{\text {rms }}$ are represented in the units of $\mathrm{cm}$ as well as the wave vectors in the region shallower than about $7.3 \mathrm{~m}$. Wave vectors are drawn at every four grid points only. The isolines are for the respective $H_{\text {rms }}$ values. Because the wave direction is indicated with vector arrows in the 16-points system $\left(22.5^{\circ}\right.$ divisions), changes in wave direction are not well represented. The wave field presented here refers to the steady state condition.

On a planar beach, little variation of wave heights occurs in the longshore direction as indicated with straight isolines of $H_{\mathrm{rms}}$ value. Two isolines of $H_{\mathrm{rms}}=140 \mathrm{~cm}$ approximately correspond to the peak of waves, and the area shoreward of the upper isoline is subjected by depth-controlled random wave breaking process. Straight isolines of wave heights are disturbed around the submerged groins, because obliquely incident waves are further dissipated by breaking at the crests of individual groins. 


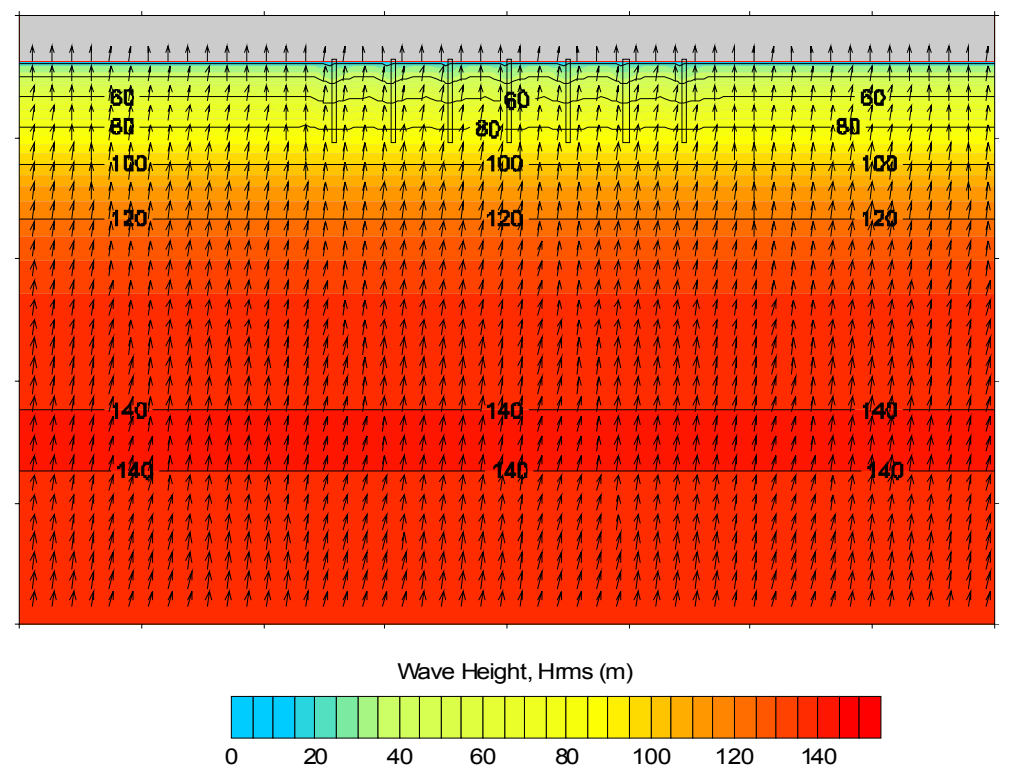

Figure 2. Spatial variation of $H_{\mathrm{rms}}(\mathrm{cm})$ and wave direction in the region shallower than $7.3 \mathrm{~m}$.

\section{Nearshore Current Field}

For the wave field shown in Fig. 2, computation of wave setup and nearshore currents is started from the still water condition with a gradual increase of the wave height at the boundary until $t=3,600$ $\mathrm{s}$ with the time step of $\Delta t=0.025 \mathrm{~s}$. Then computation is continued for another $3,600 \mathrm{~s}$ with the constant wave condition. At the stage of $t=7,200 \mathrm{~s}$, the mean water level and nearshore currents almost approach to the steady state conditions, and the output at this stage is adopted as the final result. The nearshore current field with seven submerged groins is shown in Fig. 3. Current vectors are drawn at every four grid points only. Reduction of longshore current velocities is clearly exhibited in Fig. 3.

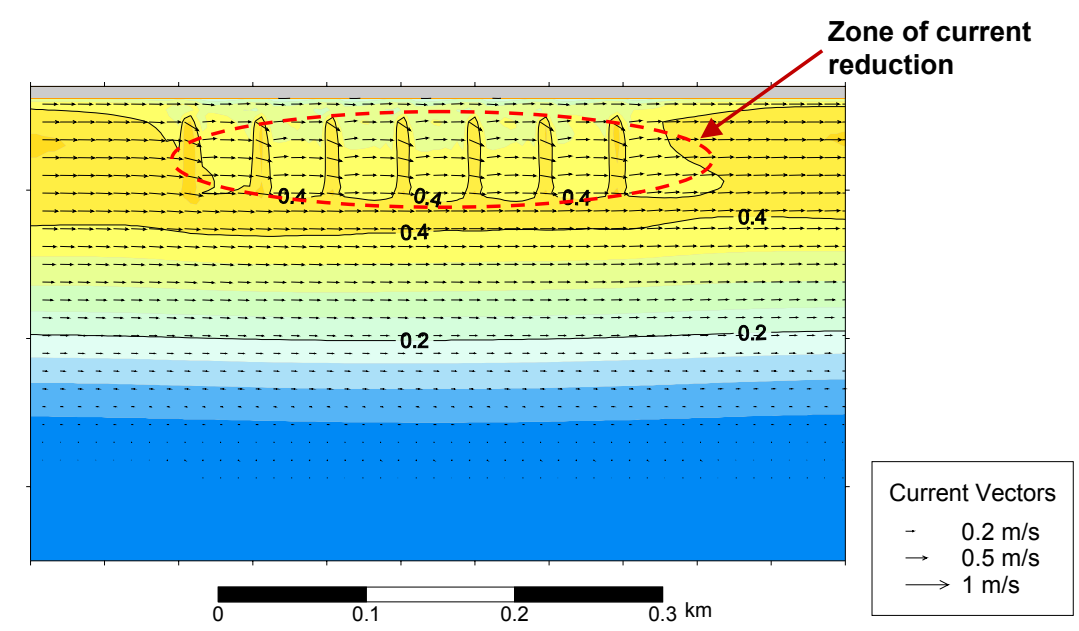

Figure 3. Spatial variation of $H_{\mathrm{rms}}(\mathrm{cm})$ and wave direction in the region shallower than $7.3 \mathrm{~m}$.

Without the groin system, the nearshore currents would have been composed of shore-parallel longshore components only with the strongest currents at the middle length of groins at the depth of around $1.4 \mathrm{~m}$. As indicated with an ellipse of red dashed line, the current speed is reduced within the groin system.

Slight offshore bulges of the isolines of the current speed of 0.2 and $0.4 \mathrm{~m} / \mathrm{s}$ indicate influence of the presence of the groin system on the overall current field. An emerged groin induces large disturbances on the nearshore current field as exhibited in Fig. 4. The length of the emerged groin is 65 $\mathrm{m}$, same as the submerged ones, and the beach profile and wave conditions are the same. In this figure, current vectors are drawn at every grid points. As clearly shown in Fig. 4, the current speed is greatly 
amplified at the groin head, and the isoline bulge of current speed is observed at the distance of more than twice the groin extension. Thus, an emerged groin system produces large disturbances on the nearshore current field and may possibly exercise adverse effect on its beach control function.

Current, $\mathrm{m} / \mathrm{s}$

$0.2 \quad 0.5 \quad 1$

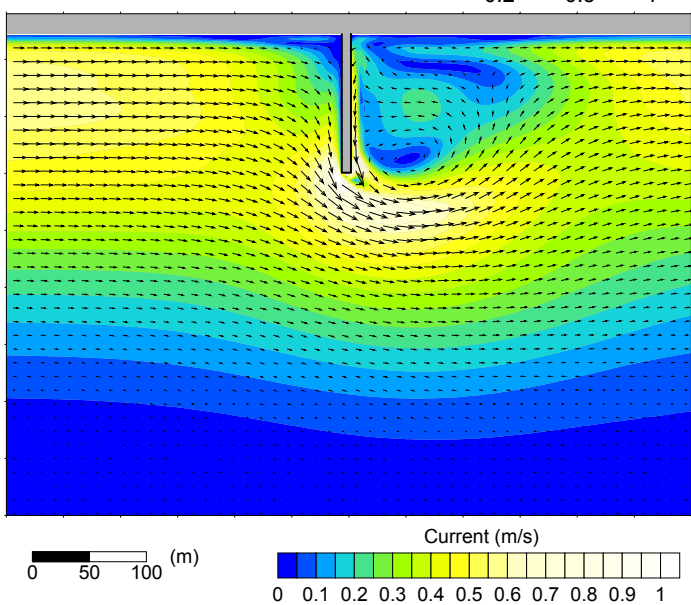

Figure 4. Nearshore current field around an emerged groin.

In comparison with the emerged groin system, the submerged groin system suppresses the speed of longshore currents in the area within the groin system and produces little influence on the area outside it.

This would be a commendable merit of a submerged groin system.

\section{Cross-shore Profiles of Longshore Currents and Sediment Transport Rate}

The effect of installation of a submerged groin system on beach is examined along the cross-shore line at the center of the groin system. Figure 5 shows comparison of the current and sediment conditions with and without the groin system. The top panel shows the cross-shore variation of sediment concentration, the middle panel is for the longshore current velocity, and the lower panel indicates the longshore sediment transport rate.
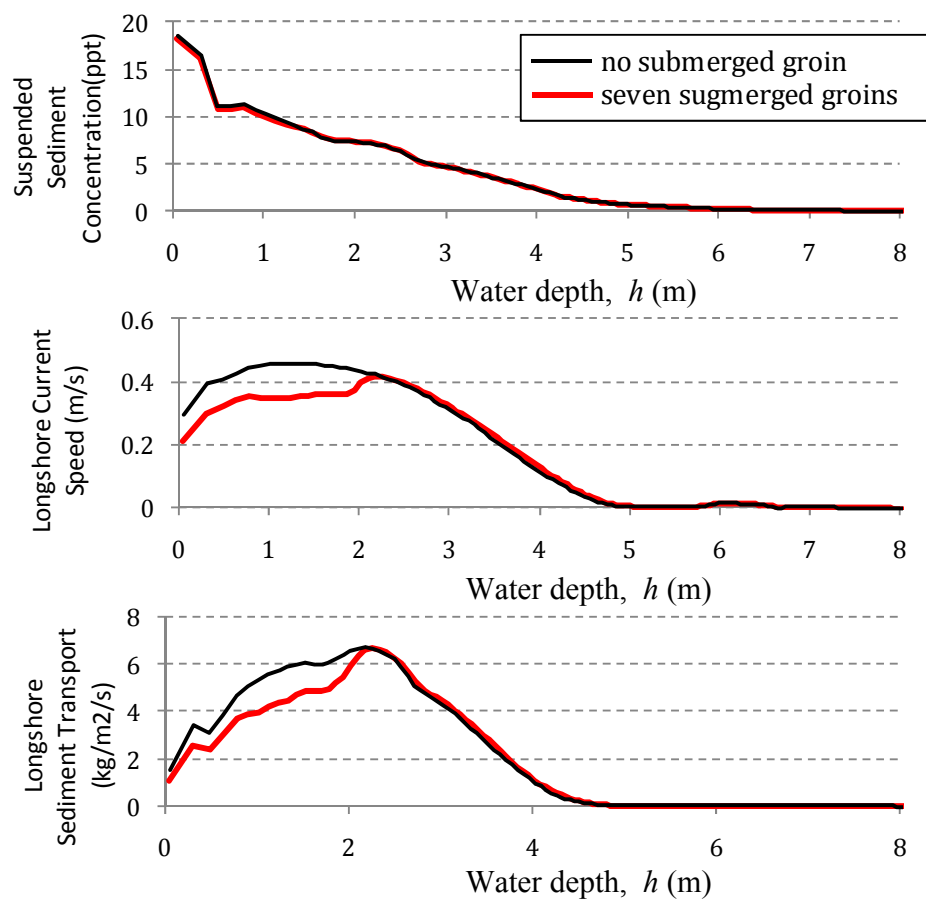

Figure 5. Comparison of the sediment and current conditions with and without submerged groins. 
The suspended sediment concentration shown in the upper panel of Fig. 5 is little affected by installation of the groin system, because the dissipation rate of wave energy flux within the groin system is almost the same as the case without submerged groins. Spatial distribution of wave energy flux dissipation rate is shown in Fig. 6(a) in the next subsection.

The longshore current velocity is markedly reduced in the area with the depth of 0 to $2 \mathrm{~m}$, where the groins are installed as shown in the middle panel of Fig. 5. This panel supplements the general current distribution of Fig. 3. The longshore sediment transport rate, which is the product of the sediment concentration and the longshore current speed, also decreases within the groin system as shown in the lower panel of Fig. 5.

\section{Wave Energy Flux Dissipation and Suspended Sediment Concentration}

The PEGBIS model enables to estimate the dissipation rate of wave energy flux, $\partial W / \partial n$, to be substituted in Eq. (8). It has been calculated as shown in Fig. 6(a). The depth-averaged sediment concentration is obtained $\bar{c}=q_{p} / w_{f}$ with $q_{p}$ being evaluated by Eq. (8). The result is shown in Fig. 6(b). The dissipation rate of wave energy flux is largest at the depth around the groin heads, while the sediment concentration becomes highest near the shoreline because it is inversely proportional to the water depth as indicated by Eq. (8).

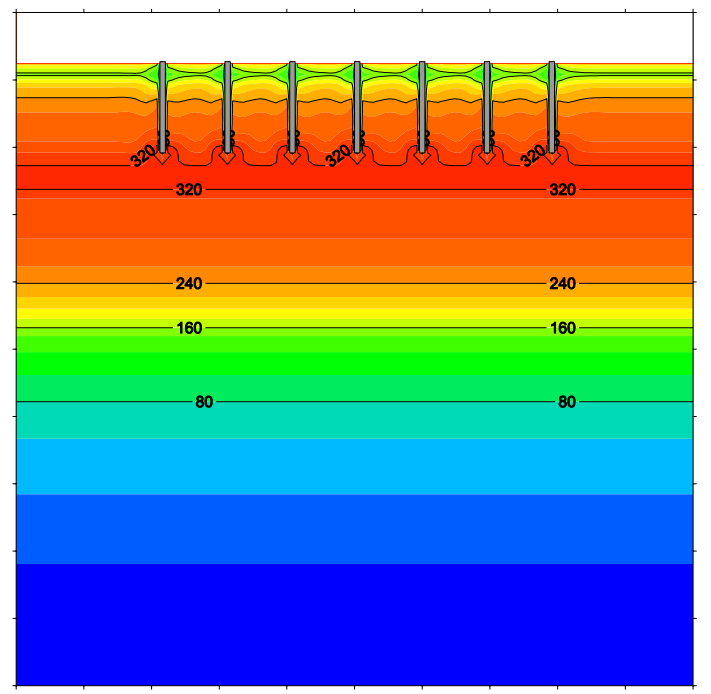

$\mathrm{dWs}\left[\mathrm{kg} / \mathrm{s}^{3}\right]$

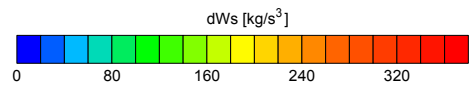

(a) Energy flux dissipation rate

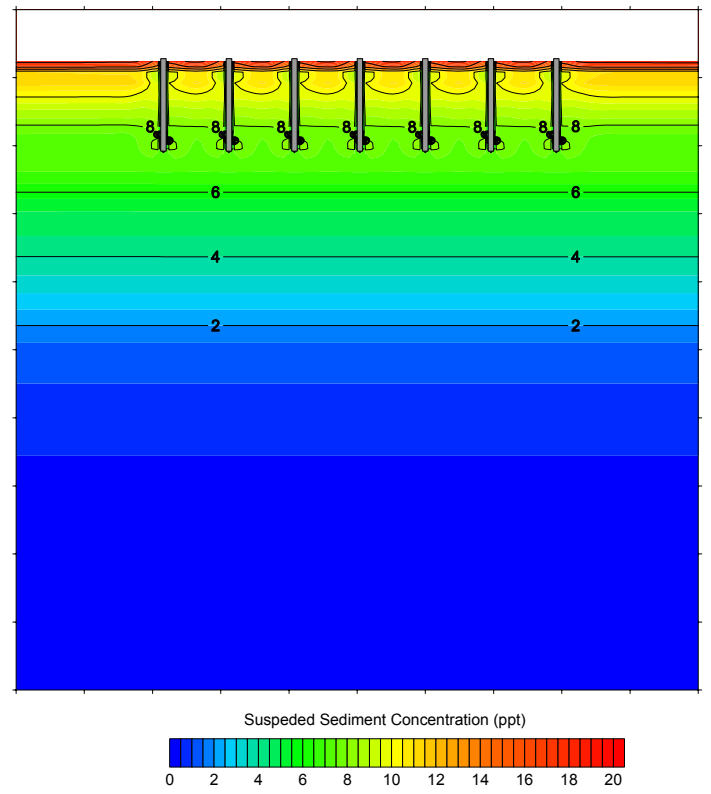

(b) Suspended sediment concentration

Figure 6. Distribution of wave energy flux dissipation rate and suspended sediment concentration.

\section{Seabed depth change}

With the sediment pickup rate evaluated by Eq. (8) and the spatial distribution of sediment concentration computed by Eq. (12), time-evolution of local depth has been calculated by Eq. (13). Computation is carried out for 3 hours in the prototype dimension to see the trend of beach morphology induced by installation of a submerged groin system shown in Fig. 1.

The result of depth change is exhibited in Fig. 7. At the downstream side to the groin heads, there appears accretion that seems to be brought forth by reduction of current speeds. Along the trunks of groins, erosion is taking place probably because of shortage of sediment supply across the crests of groins owing to the decrease in local depth. Accretion is also observed around the tails of groins, the reason of which has not been clarified yet. A slight deposition is discernible at the up-drift side of the submerged groin system. 


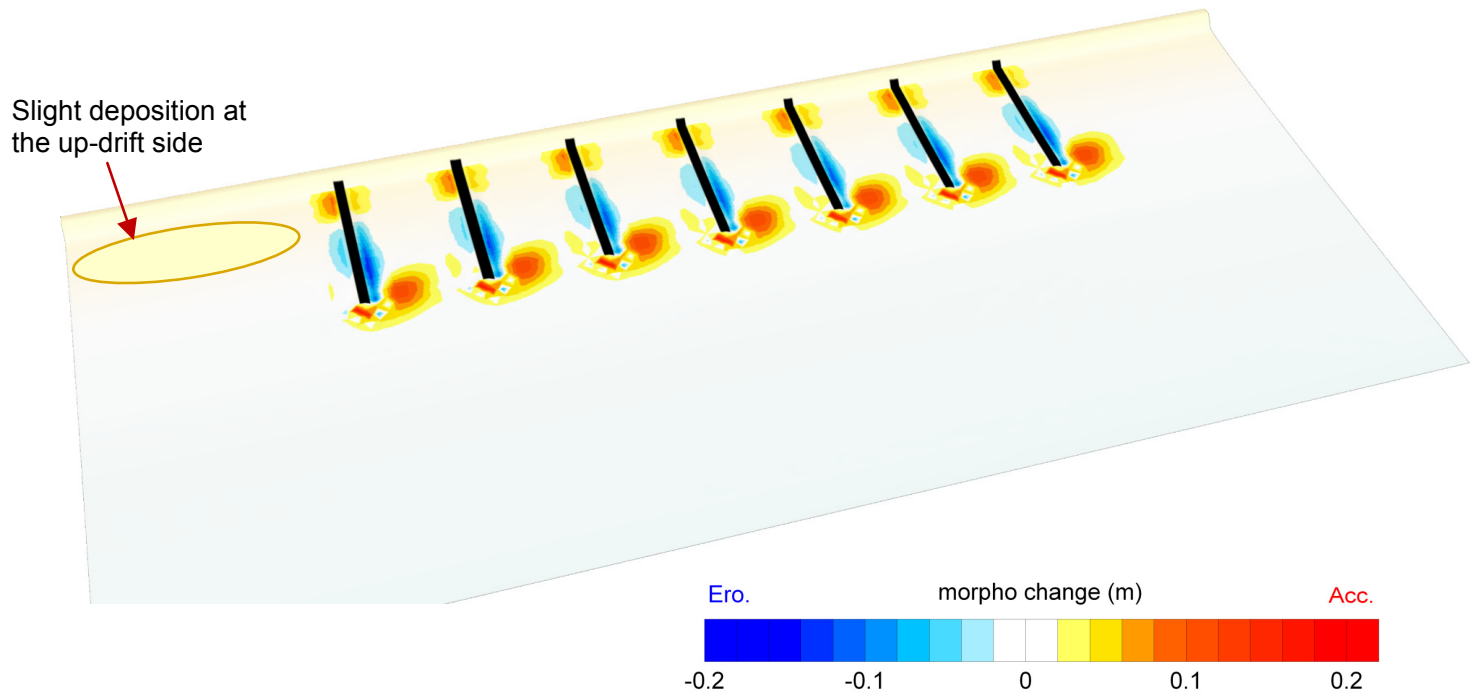

Figure 7. Snapshot of beach morphological change by installation of submerged groin system.

The result shown in Fig. 7 is a kind of snapshot of beach morphological change induced by installation of a submerged groin system. When computation is carried out for longer period, say 30 hours, a different picture will emerge. Recalculation of wave and current fields on the modified beach morphology will yield more realistic prediction on the performance of a submerged groin system on beach erosion control.

\section{DISCUSSIONS}

The present numerical simulation study had the aim of clarifying the mechanism of sand accretion between submerged groins such as claimed by Holmberg (2001) and Goudas et al. (2001). However, it has been shown that the physical process of reducing the longshore currents by itself does not induce sediment inflow from the offshore. A possible mechanism may be the onshore bed-load transport during mild waves of long periodicity and some process of restricting offshore transport by storm waves with the presence of submerged groins. Addition of the bed-load transport to the suspended sediment transport will be a way for improving the predictive capacity of the model employed in the present study.

The function of a submerged groin would be more complicated than the artificial roughness effect employed in the present study. Against the shore-parallel longshore currents, the crest of a groin induces flow separation and a system of vertical circulation should appear in the lower layer of downstream side. Turbulence of incoming breaking waves will enhance the mixing of the upper downstream flow and the lower upstream flow behind a submerged groin. Details need to be investigated through 3D measurements on a fixed bed model in laboratory.

\section{CONCLUDING REMARKS}

Numerical simulations presented in this paper have demonstrated the capability of a submerged groin system in reducing the speed of wave-induced longshore currents. Its current control capacity seems to be quite strong thanks to the artificial roughness effect. Despite minimal disturbances to the nearshore currents outside the submerged groin system, it can induce sediment accretion in the upstream side of the system. Because the system is submerged, it does not interfere with the aesthetic view of the ocean. Low construction cost also adds the merit to the system as one of soft shore protection measures.

The numerical simulation scheme reported here is a demonstration of the capability of suspendedsediment-based beach morphology model. Much more works are needed for improvement of the numerical model, computational execution of many cases, laboratory tests on the nearshore current field modified by submerged groins, and others. The authors sincerely hope that many coastal engineers would join with the authors in the study for development of a submerged groin system, which seems to be a quite promising means for beach erosion control. 


\section{REFERENCES}

Aminti, P. L., C. Cammelli, L. E. Cipriani, and E.Pranzini. 2001. Evaluating the effectiveness of a submerged groin as soft shore protection. Proc. 1st Conf. Soft Shore Protection, Patras, Greece, 151-158.

Aminti, P. L., L. Cappietti, C. D'Elso, and E. Mori. 2009. Numerical simulation of an experimental submerged groin system, Coastal Structures 2007 (Proc. 5th Int. Conf., Venice, World Scientific), pp. 1511-1519.

Del Valle, R. Medina, and M. A. Losada. 1993. Dependence of coefficient K on grain size, J. Waterway Port, Coastal, and Ocean Eng., 119 (5), 568-574.

Goda, Y. 2000. Random Seas and Design of Maritime Structures (2nd Ed.), World Scientific, Singapore, 29-34.

Goda, Y. 2004. A 2-D random wave transformation model with gradational breaker index, Coastal Engineering Journal, 46, (1), 1-38.

Goda, Y. 2006. Examination of the influence of several factors on longshore current computation with random waves, Coastal Engineering, 53 (2-3), 157-170.

Goda, Y. 2008. Wave setup and longshore currents induced by directional spectral waves: Prediction formulas based on numerical computation results. Coastal Engineering Journal, 50 (4), 397-440

Goda, Y., N. Ono, and Y. Uno. 2009. Examination of efficacy of submerged groin system against beach erosion through numerical simulation, Coastal Dynamics 2009 (Proc. 6th Int. Conf., Tokyo, World Scientific), Paper No. 41 in CD ROM, 13p.

Goda, Y. 2010. Quantitative assessment of sediment pickup rate within surf zone based on large-scale data, $J$. Coastal Engineering, JSCE, Vol. 57, pp. 421-425 (in Japanese), also to be presented at Coastal Sediments 2011 to be held in Miami, USA.

Goudas, C. L., G. A. Katsiaris, G. Labeas, G. Karahalios, and G. Pnevmatikos. 2001. Soft protection using submerged groin arrangements - dynamic analysis of system stability and review of application impacts, Proc. 1 st Conf. Soft Shore Protection, Patras, Greece, 167-186.

Holmberg, D. 2001. Alternative to traditional ways of treating shoreline erosion, Proc. 1st Conf. Soft Shore Protection, Patras, Greece, 139-150.

Katayama, H. and Y. Goda. 2000. A sediment pickup rate formula based on energy dissipation rate by random breaking, Proc. 27th Int. Conf. Coastal Eng., Sydney, ASCE, 2859-2872.

Katayama, H. and Y. Goda. 2003. 2DH beach changes due to suspended sediment picked-up by random breaking waves, Coastal Engineering 2002 (Proc. 28th Int. Conf., Cardiff, Wales, World Scientific), pp. 2767-2779.

Larson, M. and N.C. Kraus. 1991. Numerical model of longshore current for bar and trough beaches, J. Waterway, Port, Coastal, and Ocean Eng., 117 (4), 326-347.

Nishimura, H. 1982. Numerical simulation of nearshore circulations, Proc. 29th Japanese Conf. Coastal Eng., 333-337 (in Japanese).

Tajima, Y. and O.S. Madsen. 2003. Modeling near-shore waves and surface roller, Proc. 2nd Int. Conf. Asian and Pacific Coasts (APAC 2003), Makuhari, Chiba, 2003, Japan, Paper No. 28 in CD-ROM, 12p. 